\title{
Nanotopographical Control of Stem Cell Differentiation
}

\author{
Laura E. McNamara, ${ }^{1}$ Rebecca J. McMurray, ${ }^{1}$ Manus J. P. Biggs, ${ }^{2}$ Fahsai Kantawong, ${ }^{1}$ \\ Richard O. C. Oreffo, ${ }^{3}$ and Matthew J. Dalby ${ }^{1}$ \\ ${ }^{1}$ Centre for Cell Engineering, , Institute of Molecular, Cell and Systems Biology, College of Medical, Veterinary and Life Sciences, \\ University of Glasgow, Glasgow G12 8QQ, Scotland \\ ${ }^{2}$ Department of Applied Physics and Applied Mathematics, Nanotechnology Centre for Mechanics in Regenerative Medicine, \\ Columbia University, 1020 Schapiro CEPSR, 530 West 120th St., MC 8903, New York, NY 10027, USA \\ ${ }^{3}$ Bone and Joint Research Group, Centre for Human Development, Stem Cells and Regeneration, Institute of Developmental Sciences, \\ University of Southampton, Southampton, Hants SO16 6YD, UK
}

Correspondence should be addressed to Laura E. McNamara, Laura.McNamara@glasgow.ac.uk

Received 31 May 2010; Accepted 16 July 2010

Academic Editor: Vehid Salih

Copyright ( 2010 Laura E. McNamara et al. This is an open access article distributed under the Creative Commons Attribution License, which permits unrestricted use, distribution, and reproduction in any medium, provided the original work is properly cited.

Stem cells have the capacity to differentiate into various lineages, and the ability to reliably direct stem cell fate determination would have tremendous potential for basic research and clinical therapy. Nanotopography provides a useful tool for guiding differentiation, as the features are more durable than surface chemistry and can be modified in size and shape to suit the desired application. In this paper, nanotopography is examined as a means to guide differentiation, and its application is described in the context of different subsets of stem cells, with a particular focus on skeletal (mesenchymal) stem cells. To address the mechanistic basis underlying the topographical effects on stem cells, the likely contributions of indirect (biochemical signalmediated) and direct (force-mediated) mechanotransduction are discussed. Data from proteomic research is also outlined in relation to topography-mediated fate determination, as this approach provides insight into the global molecular changes at the level of the functional effectors.

\section{Introduction}

It is becoming increasingly evident that stem cells are highly sensitive to their environment and will respond to cues provided by chemistry [1], stiffness in two- [2] and threedimensional (3D) culture [3], and topography $[4,5]$. This paper will focus on stem cell (primarily skeletal stem cell) responses to nanotopography and its mechanistic basis.

The natural environment of the cell has complex chemical and topographical cues, which will differ between a structured surface and the uncharacterised surfaces normally used for in vitro culture. Cells may encounter different sizes of topographies, ranging from macro- (such as the shape of bone, ligaments, or vessels), to micro- (such as the arrangement, morphology, and projections of other cells) and nanoscale features (such as collagen banding, protein conformation, and ligand presentation) $[6,7]$, each of which has the potential to influence cell behaviour and functionality. An early study by Carrel and Burrows in 1911 showed that cells were responsive to shape cues [8], and over the last decade, the effects of microtopography have been well documented. Microtopographies, which include micropits, microgrooves, and micropillars, frequently guide the cell body by physical confinement or alignment. These substrata can induce changes in cell attachment, spreading, contact guidance, cytoskeletal architecture, nuclear shape, nuclear orientation, programmed cell death, macrophage activation, transcript levels, and protein abundance [9-14].

Critically, evidence is also gathering on the importance of nanoscale dimensions in the design of the next generation of tissue-engineering materials, as these features are capable of modulating cell responses. Interaction with nanotopographies can alter cell morphology [15], adhesion [16], motility [17], proliferation [18], endocytotic activity [19], protein abundance [20, 21], and gene regulation [22]. Nanotopographical responsiveness has been observed in 
diverse cell types including fibroblasts $[18,22]$, osteoblasts [23], osteoclasts $[24,25]$, endothelial [15], smooth muscle [26], epithelial $[27,28]$, and epitenon cells [16]. This is intriguing from a biomaterials perspective as it demonstrates that surface features of just a few nanometres can influence how cells will respond to, and form tissue on, materials. To date, the smallest feature size shown to affect cell behaviour was $10 \mathrm{~nm}$ [29], which illustrates the importance of considering the topographical cues deliberately or inadvertently presented to cells during in vitro culture and implantation of devices. As a growing number of precision nanofabrication techniques become available to the stem cell biologist, including electron beam lithography [30, 31], photolithography [32], polymer phase separation [33, 34], and colloidal lithography [35], it becomes possible to begin to dissect out the effects of nanotopography on stem cells and use the materials as noninvasive tools to investigate cellular functioning.

\section{Stem Cells and Topography}

The use of topographically patterned substrates for culturing cells has one clear advantage over the use of defined mediait allows cell growth and development to be tailored to a specific application without the need to use potentially harmful chemicals in the body. Tissue engineering successes with terminally differentiated cells include the generation of skin [36], tissue-engineered airway [37], and a whole bladder [38]. The use of stem cells in tissue engineering not only opens up the potential to produce patient-specific tissues, reducing the risk of immune rejection, but through the understanding of material properties that elicit specific responses could in the future allow the formation of complex tissues.

Stem cells, including embryonic, foetal, and adult, have two key properties: (1) the ability to self renew and (2) they are undifferentiated. One main difference between embryonic and adult stem cells, however, is that embryonic stem (ES) cells are pluripotent and therefore have the ability to form all three germ layers: ectoderm, endoderm and mesoderm whereas adult stem cells are considered multipotent and normally only have the ability to replenish cell types present in their tissue of residence. Ethical issues surrounding ES cells, as well as the relative accessibility of adult stem cells, make adult stem cells a more desirable target. Embryonic stem cells also require a feeder layer (mouse embryonic fibroblasts (MEFs)) when cultured in vitro, which helps to maintain the stem cells' self-renewal and proliferative capacity but makes ES cells less feasible as an experimental system due to the risk of transmitting viral infections. As the development of cultures without the need for feeder layers becomes more prevalent, this may change [39]. Adult stem cells include skeletal (also known as mesenchymal), neural, and haematopoietic stem cells. Induced pluripotent stem cells have recently emerged as an exciting further avenue to study adult stem cells induced to become pluripotent embryonic-like cells [40-42].
2.1. Embryonic Stem Cells. The main aims of biomaterials for stem cell culture are to provide cues that direct the differentiation of stem cells into a specific cell lineage and to allow the stem cells to remain undifferentiated but still undergo proliferation and self-renewal. Embryonic stem cell response to topography has been documented in terms of both controlled differentiation $[43,44]$ and retention of selfrenewal/proliferative capabilities. On the latter topic, one such paper examined the effect of grooves with varying pitch from $400 \mathrm{~nm}$ up to the microscale at $4000 \mathrm{~nm}$ on human ES cell differentiation and self-renewal in the presence and absence of a feeder layer [44]. In culture, ES cells are prone to spontaneous differentiation, leading to a reduction in their self-renewal and pluripotent capacity. McFarlin et al. (2006) [45] showed that culture of human ES cells on nanogrooves in the presence of a feeder layer significantly reduces the rate of spontaneous differentiation relative to ES cells cultured on feeder layers alone [44]. Interestingly, however, they also reported that when ES cells were cultured on the nanogrooves in the absence of a feeder layer, the rate of spontaneous differentiation increased compared with those cultured with only a feeder layer. These results indicate that ES cells may be influenced by topography in a contextual manner, and their response therefore also depends on other external factors.

The ability to control self-renewal and proliferation of ES cells using topography has also been studied using mouse ES cells in response to 3D nanofibres but importantly in the presence of only $5 \%$ of the original feeder layer MEFs [45, 46]. The study showed that mouse ES cells cultured on the 3D nanofibrillar surfaces had an increased rate of proliferation in comparison with those cultured solely on glass coverslips. The authors noted raised Nanog levels on the 3D nanofibres, and Nanog is a protein required for the maintenance of stem cell pluripotency. These results indicate that the $3 \mathrm{D}$ nanofibre structures may provide an alternative method for maintaining self-renewal and proliferation capacities in mouse ES cells as effectively as feeder layers alone.

2.2. Skeletal Stem Cells. Skeletal stem cells [47], found in the bone marrow, have been shown to differentiate into various cell types including osteoblasts, adipocytes [48], chondrocytes [49], smooth muscle cells [2, 50], and, controversially, neurons $[51,52]$. In most of these cases, however, differentiation of the stem cells has required the use of differentiation factors, such as dexamethasone for osteogenic differentiation, insulin for adipogenic differentiation, and hydrocortisone for smooth muscle cell differentiation. There is now compelling evidence that topography alone can produce the same effect. This is particularly attractive given that induction by some of these medium supplements, although successful, is not physiologically relevant and offers the possibility for development of improved clinical prostheses with topographies that can directly modulate stem cell fate.

The effect of nanotopographical variation on the differentiation of skeletal stem cells has been noted in several key studies. The first of these examined Stro-1 enriched skeletal stem cells cultured on nanopits $(120 \mathrm{~nm}$ diameter, $100 \mathrm{~nm}$ 
depth) with varying degrees of disorder and geometry, ranging from an absolute square and controlled disorder to a random arrangement embossed into the polymer polymethylmethacrylate (PMMA) [4]. Key observations of this study were that when cultured specifically on nanopits with a controlled disorder of $\pm 50 \mathrm{~nm}$ (NSQ50) from their true centre, skeletal stem cells expressed particularly high levels of bone cell markers (Figure 1). This was comparable with the results from stem cells cultured on control planar substrates in medium supplemented with dexamethasone and ascorbic acid, a chemical enhancer of skeletal stem cell differentiation down the osteogenic lineage, but in contrast to that of the square or random topographies. Skeletal stem cells cultured on planar control substrates without osteogenic medium had negligible amounts of bone cell markers and appeared to have a bipolar fibroblastic-like appearance. Further evidence gathered from quantitative real-time PCR (polymerase chain reaction) and microarray data revealed an increase in expression of genes associated with bone cell development, comparable with those in cells on the flat surface in osteogenic medium, and considerably higher than expression levels from cells on the supplementfree planar controls.

In a followup study, a temporal differentiation profile of skeletal stem cells cultured on the osteoinductive NSQ50 topography was carried out in reference to the classical osteogenic differentiation profile laid out by Stein and Lian [53]. This study examined the skeletal stem cell markers Stro- 1 and ALCAM (activated leukocyte cell adhesion molecule), together with the bone cell markers osteocalcin and osteopontin, to examine the progression from an undifferentiated stem cell towards a committed bone cell. It was found that the skeletal stem cells cultured on the NSQ50 topography had a normal differentiation profile in line with the proposed osteogenic differentiation model. This provides further evidence that differentiation of skeletal stem cells cultured on nanotopography can produce an equally effective, if not superior, method for differentiation than chemical induction [54].

A recent study of the effect of carbon nanotube dimensions on skeletal stem cell fate revealed that by increasing the diameter size of the nanotubes from a range of $30 \mathrm{~nm}$ up to $100 \mathrm{~nm}$, it was possible to alter the adhesion, elongation, and differentiation of these stem cells [5]. It was shown that the $30 \mathrm{~nm}$ nanotubes had a higher number of adherent cells with a more rounded morphology, in contrast to that of the stem cells cultured on the $100 \mathrm{~nm}$ nanotubes, which developed highly elongated morphologies with a low level of cell adhesion. Osteogenic differentiation of the skeletal stem cells in this study was observed to occur on the carbon nanotubes with a $100 \mathrm{~nm}$ diameter, with negligible amounts of osteogenic markers observed on carbon nanotubes of $50 \mathrm{~nm}$ or less. Interestingly, the authors also investigated the relationship between pore size and initial cell density, relating to work performed by Pittenger et al. (1999) [48] and McBeath et al. (2004) [1] which indicated that a lower seeding density led to skeletal stem cell differentiation into osteoblasts, with a higher seeding density predisposing differentiation into adipocytes. Oh et al. (2009) [5] discovered that there was an inverse correlation between pore size and cell density as found on the $100 \mathrm{~nm}$ nanotubes, which ultimately led to an increase in osteogenic gene expression, consistent with the study by McBeath et al. (2004) [1].

In a further study, skeletal stem cells were shown to differentiate down a nonskeletal lineage, a process known as transdifferentiation and a somewhat controversial topic. The skeletal stem cells were seen to differentiate down a neuronal lineage as evidenced by the upregulation of mature neuronal cell markers, MAP2 (microtubule-associated protein 2) and $\beta$-tubulin III, when cultured on nanogratings of $350 \mathrm{~nm}$ depth and $700 \mathrm{~nm}$ pitch, in the absence of neuronal differentiation medium [52]. Pitch is a term used to describe the repeating unit comprised of a groove and a ridge (in this case, both were $350 \mathrm{~nm}$ wide). These substrates induced alignment of the nuclei and cytoskeletal filaments. Quantitative realtime PCR also showed that expression of MAP2 was consistently higher in skeletal stem cells cultured over 14 days on the nanotopography without retinoic acid, a neuronal differentiation factor, than that of skeletal stem cells cultured on planar PDMS (poly(dimethylsiloxane)) supplemented with retinoic acid. This indicated that nanotopography alone might have a stronger influence upon skeletal stem cell differentiation than chemical induction alone. Interestingly, a later study showed that ES cells could also be prompted to differentiate along a neuronal lineage on nanogrooved substrates of $500 \mathrm{~nm}$ depth and $700 \mathrm{~nm}$ pitch [55], which confirmed that nanogrooved cues are useful for stimulating the development of neural tissue.

Recently, low oxygen conditions ( $2 \%$ oxygen) were used in the culture of skeletal stem cells on nanogrooves $(250 \mathrm{~nm}$ depth, $700 \mathrm{~nm}$ pitch). The low oxygen tension promoted the retention of stem cell markers including Oct-4 and Sox2 for longer than under normoxic conditions and reduced cell clustering and spontaneous differentiation, allowing the formation of a confluent monolayer [56]. The low oxygen conditions enhanced cell alignment to the nanogrooves and increased ECM secretion, but the nuclei were less elongate on the nanogrooved substrate under hypoxic conditions. The authors proposed that increased ECM production reduced the need for cell elongation, and that the altered tension could be contributing to changes in gene expression. The potential mechanistic basis of such tensional effects will be discussed in the next section. The hypoxia study, and research by McFarlin et al. (2006) [45], suggested that in vitro culture conditions should be explored in greater depth to gain a deeper understanding of the cellular response to topography. Such knowledge would have the potential to enhance the utility and efficacy of nanotopography in translational research.

2.3. Neural Stem Cells. Neural stem cells found in the brain are known to give rise to three types of cells: neurons, astrocytes, and oligodendrocytes. The latter two are classed as nonneural cells, but function in the support and protection of neurons. As mentioned previously, the two main aims of biomaterials are to provide cues for directed differentiation, and secondly, to retain proliferation without differentiation. In the following example, both of these criteria were met 


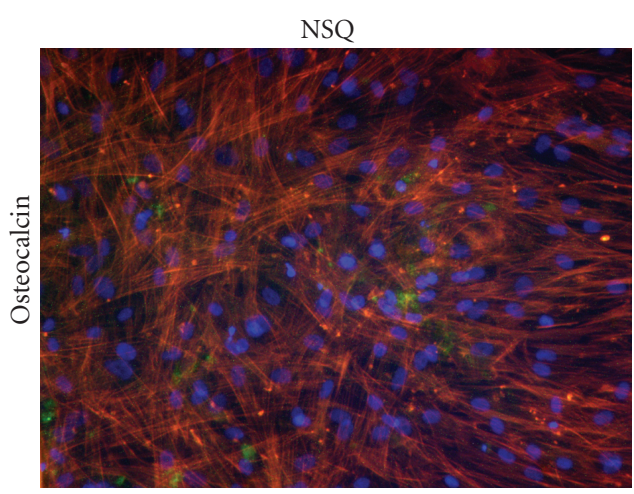

(a)

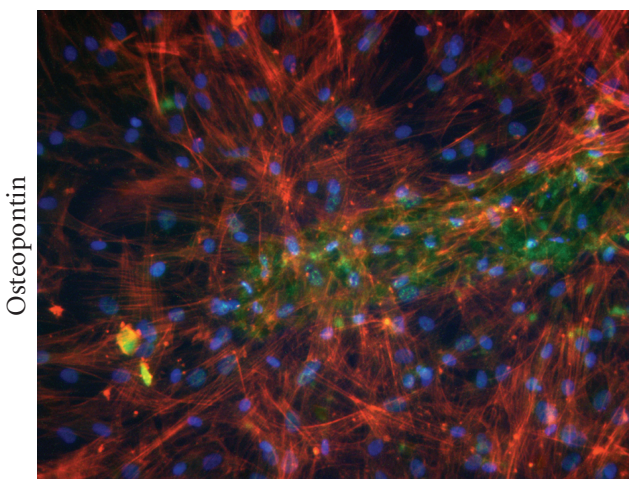

(c)

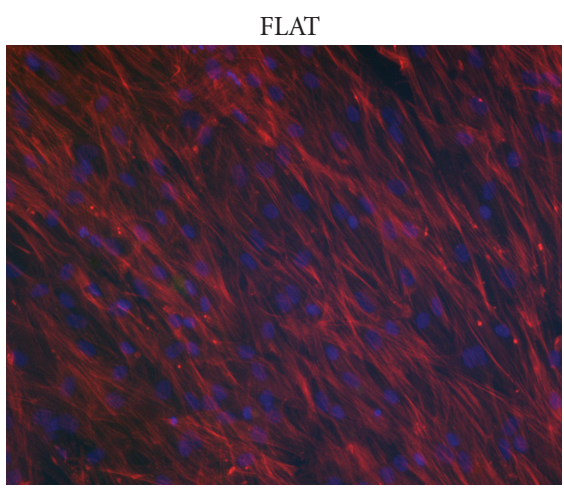

(b)

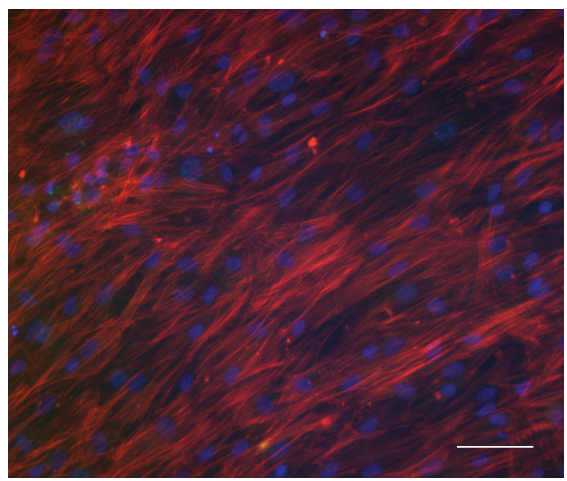

(d)

FIGURE 1: Bone protein expression in skeletal stem cells cultured on osteoinductive nanotopography. Skeletal stem cells cultured for 28 days on NSQ50 nanopits (a, c) or planar controls (b, d) and stained using immunofluorescence for bone cell markers osteocalcin (a, b; green) or osteopontin (c, d; green), with co-staining for actin (red) and nuclei (DNA-blue). Bar: $100 \mu \mathrm{m}$.

by polymer films with a honeycomb-like microtopography [57]. By varying the pore diameter of the honeycomb film it was possible to control whether rat neural stem cells differentiated into neurons, as indicated by expression of MAP2, or whether proliferation could occur without differentiation, as indicated by the expression of Nestin, a neuronal stem cell marker. It was found that by increasing the pore size of the honeycomb film above $5 \mu \mathrm{m}$, this enhanced the differentiation of neuronal stem cells into mature neurons with the effect being more prominent as the pore size was increased to $15 \mu \mathrm{m}$. In contrast, pore sizes below $5 \mu \mathrm{m}$ suppressed differentiation, with the majority of cells expressing Nestin in the absence of MAP2. Neuronal stem cell differentiation has also been shown to occur on micropatterned grooved substrates [58] and electrospun fibres [59].

\section{The Mechanistic Basis of Stem Cell Response to Topography}

The ability to control stem cell differentiation using topography alone has focused attention on elucidating the mechanism by which a cell perceives these topographical cues and relays this information into the nucleus to initiate a cellular response. A key idea that appears to be corroborated in each of the papers outlined in the previous section is the influence of cell adhesion to the topography. It has been proposed, for example, that the effects of nanotubes on skeletal stem cells [5] and on cell attachment to honeycomb films [60] were due to alterations in the surface area available for protein adsorption, restricting extracellular matrix (ECM) deposition and therefore the size of the initial cell adhesions that can form.

Focal adhesions, the sites of cell attachment to the underlying substrate, play a pivotal role in all subsequent cell actions in response to nanotopography. These dynamic adhesions are subject to complex regulation involving integrin binding to ECM components, and the reinforcement of the adhesion plaque by recruitment of additional proteins. In addition to their adhesive functions, integrins mediate bidirectional signalling between the cell and the ECM, activating both direct mechanotransductive signalling and indirect molecular cascades that regulate transcription factor activity, gene and protein expression, and ultimately growth and differentiation, as will be discussed in the following sections.

3.1. Cell Adhesions. The initiating event in tissue neogenesis is the transition of a pluri- or multipotent cell population into tissue-forming, differentiated cells-a process controlled by sequential activation of diverse signalling pathways 
and transcription factors that regulate the expression of specific genes. It is becoming increasingly clear that epigenetic modulation of cellular behaviour and subsequent cellular differentiation is highly regulated by mechanotransductive events, and that topographical modification may be a viable strategy to regulate this process.

Studies to date indicate that integrin clustering and the formation of focal adhesions are modulated by nanofeatures in vitro [61-63], and that subsequent changes in both focal adhesion density and length are linked to changes in stem cell function and differentiation [64, 65]. Topographic features, such as pillars, islands, or pits, with an interfeature or z-scale dimension greater than 50-60 nm impair focal adhesion formation and the cell response (Figure 2(a)) [62, 66-68]. Conversely, decreasing the interfeature distance or $\mathrm{z}$-dimension beyond $50 \mathrm{~nm}$ or increasing to the microscale facilitates stem cell adhesion and functional differentiation $[69,70]$. The focal adhesion plaque undergoes anisotropic growth with increased intracellular tension leading to elongation and integrin clustering. Critically, this elongation is associated with both an increase in cytoskeletal strengthening and the recruitment of focal adhesion-associated signalling molecules (Figure 2(b)).

The integrin-dependent signalling pathway is mediated by nonreceptor tyrosine kinases [71], most notably focal adhesion kinase (FAK), which is constitutively associated with the $\beta$-integrin subunit. FAK localises at focal adhesions or focal contacts and can influence cellular transcriptional events through adhesion-dependent phosphorylation of downstream signalling molecules. In particular, the extracellular signal-regulated kinase (ERK) signalling cascade $[72,73]$, a member of the mitogen-activated protein kinase (MAPK) family of pathways, is activated by focal adhesion elongation and acts as a mediator of cellular differentiation [74]. Furthermore, it has been shown that ERK $1 / 2$ is translocated to the nucleus in cells cultured on topographical features [75] and that this affects the expression of cellular transcription factors and modulates differential function [76].

Primitive cells of the embryonic inner cell mass undergo integrin-dependent activation of ERK1/2 during early gastrulation, inducing cellular differentiation and the formation of the primitive endoderm [77]. Yee et al. (2008) proposed an elegant model to explain how ERK signalling might become activated through increased binding of $\alpha_{5} \beta_{1}$ integrins to extracellular matrix proteins [78], whereby increased FAK recruitment to the adhesion plaque induces downstream ERK-dependent differentiation. This model not only provides an insight to the mechanisms of focal adhesion-dependent differentiation, but more importantly, also indicates that nanotopographical surface modification may directly regulate stem cell differentiation.

Functional differentiation in skeletal stem cell populations is highly dependent on focal adhesion formation and cellular spreading, processes which are, to a degree, dependent on nanotopographical cues [79]. Indeed, it has been reported that adipogenic differentiation of skeletal stem cells versus osteospecific differentiation is directly related to cellular spreading [1]. It can be inferred that nanoscale features influence differential pathways in adherent stem cell populations by modulating integrin clustering and adhesion formation [80], and that subsequent activation of FAK acts to regulate the ERK signalling pathway and influence stem cell differentiation and tissue neogenesis. Indeed, recent studies suggest that phosphorylation of both FAK and ERK is influenced by nanoscale topography $[65,81]$, and that FAK activity indirectly regulates stem cell differentiation [82]. Further to this, both ERK signalling and focal adhesion formation are decreased in skeletal stem cell populations cultured on topographical features that approach $100 \mathrm{~nm}$ in height [64].

In the previous section, studies were discussed that illustrated that skeletal stem cells could preferentially differentiate into either osteoblasts or adipocytes as an effect of variations in cell seeding density. This is possible because adipogenic and osteogenic cells share part of the early differentiation cascade followed by other, partly unknown, signals that determine commitment to one of these lineages. Studies suggest that a reduction in cellular adhesion, cytoskeletal development, and deactivation of FAK induce adipospecific differentiation $[83,84]$, perhaps indicating that antiadhesive nanotopographies may be employed to direct progenitor cell differentiation [85] and reduce osteospecific differentiation. Conversely, nanotopographical modification that induces an increase in integrin-substratum interaction and cellular spreading may be employed to induce osteospecific differentiation. Indeed, mesenchymal stem cells have been shown to undergo osteospecific differentiation and functional tissue formation when cultured on nanoscale topographies, which increase focal adhesion frequency and elongation (Figure 2) $[70,86]$.

3.2. Mechanotransduction. Modulation of focal adhesions will alter cellular mechanotransduction, which is described in more detail in this section. Mechanotransduction is the process by which external mechanical stimuli (including cell stretch, compression, and interaction with topography) are transmitted into the nucleus, resulting in adaptive gene- and protein-level changes. As has been discussed, signalling cascades can be induced at focal adhesions, leading to indirect downstream effects on gene expression. Direct mechanotransduction, in contrast, involves physical pulling of the cytoskeleton on the nucleus, and has the potential to modify gene transcription by imposing mechanical forces on nuclear components. This section will focus on the lesserknown direct mechanotransduction.

Nanotopography presents nanoscale features to cells that can lead to changes in the number, size, and arrangement of focal adhesions [80], redistribution of cyto- and nucleoskeletal elements [63], and altered cell and nuclear morphologies [63]. Thus, nanostructured surfaces induce rearrangements of cellular architecture that promote both signalling effects and direct mechanical changes in the cell. This combination of chemical signals and physical forces leads to the changes in transcript and protein abundance that have been observed using microarray studies of various cell types on nanopits [87], nanopillars [63], nanoislands [22], nanogrooves [65], and partially disordered nanopatterns [4], and a proteomic 


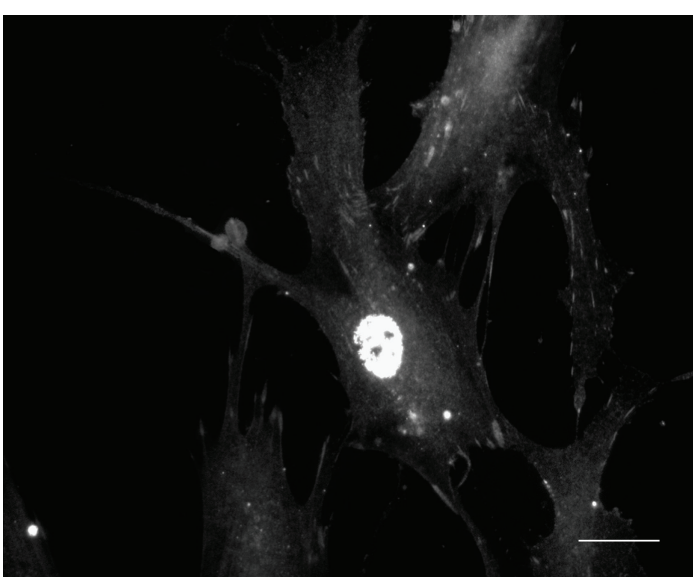

(a)

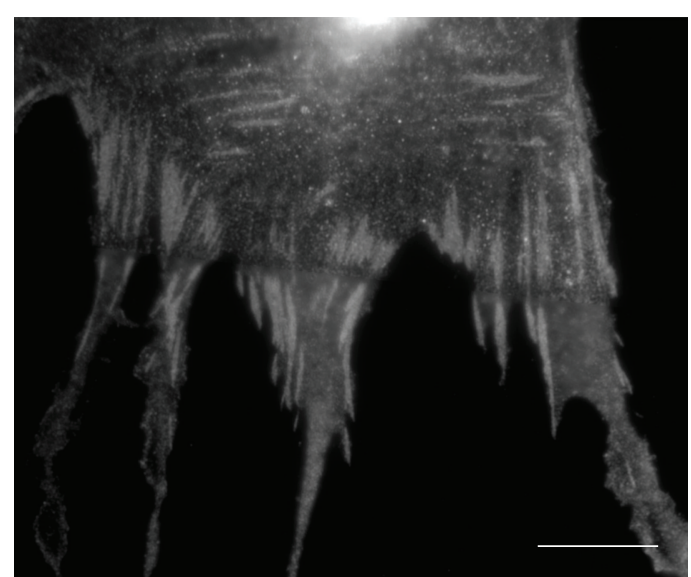

(b)

FIGURE 2: Nanotopographical control of focal adhesion formation in human osteoblast cells. (a) Focal adhesion length and frequency are reduced on $100 \mathrm{~nm}$ deep nanopit substrates which inhibit integrin clustering. (b) Conversely, $300 \mathrm{~nm}$ high nanostep topographies facilitate integrin clustering and "supermature" adhesion elongation. Bar: $30 \mu \mathrm{m}$.

examination of osteoprogenitor response to nanodisordered surfaces [20].

Signalling cascades are initiated by exertion of mechanical forces at focal adhesions, leading to sequential posttranslational modification (principally phosphorylation) events that transfer the message into the nucleus, and stimulate transcriptional effects. Focal adhesions are critical inducers of downstream signalling in response to nanotopography. Physical pulling on focal adhesions can promote their growth in response to tyrosine phosphorylation of the GTPase Rho [88], which illustrates the mechanosensitivity of these sites. As discussed earlier, adhesions are linked to the extracellular matrix via integrins, which are capable of bidirectional signalling, and can become cross-linked in response to mechanical force [89]. These sites are rich in vinculin and possess kinases such as FAK [90]. The protein composition of adhesions has been shown to change in response to mechanical stretch, which was demonstrated using binding assays in extracted cytoskeletons and green fluorescent protein(GFP-) tagged protein localization studies [91]. Tension can also induce conformational changes in focal adhesion proteins. It has been shown, for example, that tensile force could modify the shape of talin, allowing it to bind additional vinculin [92], and the functionality of the adapter protein p130Cas in the promotion of integrin signalling [93]. Tensile strain has been shown to promote relocation of a transcriptional coactivator (myocardin-related transcription factor A) from the cytoplasm into the nucleus, via a Rhodependent pathway [94]. Cells also possess mechanosensitive ion channels that induce cellular ion fluxes in response to mechanical events, and it is likely that these channels will contribute to the cellular response to nanotopography. A model was proposed to explain the induction of signalling events following interaction with nanopits and nanopillars, in which a family of proteins that are sensitive to membrane conformation detect the distension of the membrane into nanopits, while its extension over nanopillars may be sensed by the force-induced opening of ion channels [95].

Direct mechanotransduction requires transmission of force into the nucleus in order to exert a physical change. In tensegrity theory, the cytoskeletal elements are described in terms of their likely contribution to force transmission. In this model, actin stress fibres generate tension while microtubules can bear compression. These opposing forces, together with a contribution from the intermediate filaments (such as vimentin and the nucleoskeletal lamins) provide "prestress" to the cellular tensegrity structure [96]. The cytoskeleton is physically linked to the nucleoskeleton via bridging proteins including SUN (Sad1p-Unc-84) and the nesprins [97]. On the nucleoplasmic side, DNA is physically associated with the lamina, at sites called matrix attachment regions (MARs). Kilian et al. (2010) used chemical surface patterning to confine cell morphology in an analogous manner to surface topography, with angular patterns inducing osteogenic differentiation, and rounded adhesive patterns (printed in flower or circular shapes) increasing adipospecific differentiation [98]. Myosin II staining suggested that cytoskeletal tension had been decreased in cells on rounded patterns and enriched in cells on the more angular shapes. Such differentials of tensile force could impact upon the positioning of chromosomes, by unequal distribution of mechanical forces onto the nucleus via attachment to the nucleoskeleton. Similarly, the enclosure of multipotent stem cells within 3D gels of variable stiffness containing adhesive peptides modulated fate determination by affecting the extent to which the cells were able to cluster adhesive ligands, and exert a contractile force upon the substrata [3]. Such tension would be expected to affect the nucleus, and ablation experiments have suggested that heterochromatin is important in the structural maintenance of nuclear architecture [99]. Heterochromatin would probably also contribute to force transmission from the cytoskeleton into the nucleus, via its association with the nuclear lamina. 
In general, the peripheral DNA at the edge of the nucleus is comprised of such rarely transcribed-or transcriptionally silent-heterochromatin, while the more frequently expressed sequences are typically more centrally located. Extraction experiments have supported a mechanical link between chromosomes and nucleoli [100], and an interesting study was performed using micromanipulation of cells [101], where pulling exerted at the peripheral cytoplasm resulted in relocation of the nucleus and concurrent redistribution of nucleoli. It was concluded that the force had been transmitted between the interconnected cytoskeleton and nucleoskeleton. The use of nanotopography as a mechanoinducing signal has the additional advantage that it is a noninvasive stimulus, and thus cells are not damaged, unlike in such traditional interventional approaches. FISH (Fluorescence in situ hybridisation) was used to examine the centromeric positioning of chromosome 3 in the interphase nuclei of fibroblasts cultured on nanocolumns [63]. Compared with cells on planar controls, cells cultured on nanotopography were less well spread, and had nuclei that appeared smaller with more closely apposed centromeres. These alterations are consistent with topography-induced direct mechanotransduction, as the authors proposed that the decrease in nuclear surface area and interchromosomal distances on the structured surfaces could be due to decreased cell spreading, resulting in less taut cytoskeletons, lowered tensile forces and reduced pulling on the nuclei. Chromosomal redistribution has the potential to affect gene transcription if the chromosomes are nudged, for example, from hetero- to euchromatic regions of the nucleus. This would necessitate derepression of silenced chromosomal regions, including relaxation of condensed histones and/or removal of epigenetic marks for gene silencing, with the addition of marks promoting gene activity (discussed in [102]).

Recently, a number of models have been proposed to explain how tension from focal adhesions could be converted into gene- or protein-level effects [103]. The authors suggested that DNA might be subject to local melting at MARs, allowing increased access for transcription factors, or that matrix distension may influence the effect of transcription factors. Alternatively, the authors suggest that tensile strain could directly modulate the assembly of transcription factor complexes, or that nuclear pores could be affected, leading to alteration of mRNA transport. The mechanical changes exerted by nanotopography will most likely have multiple, synergistic effects on the nucleus for the enforcement of gene-level changes. It is also probable that topography-invoked mechanotransduction will have various outputs, acting at both the mRNA and protein levels (Figure 3): (1) transcriptional, with the physical accessibility of genes to transcription factors being altered, (2) posttranscriptional, with effects on mRNA splicing, editing or transport, (3) translational, by altering protein production, (4) post-translational, by rapidly altering the activity state of proteins, and (5) conformational, with changes in protein structure, composition of protein assemblies, and exposure of cryptic binding sites.

In this complex interplay, the complementary nature of direct and indirect (chemical signal-mediated) mechan-

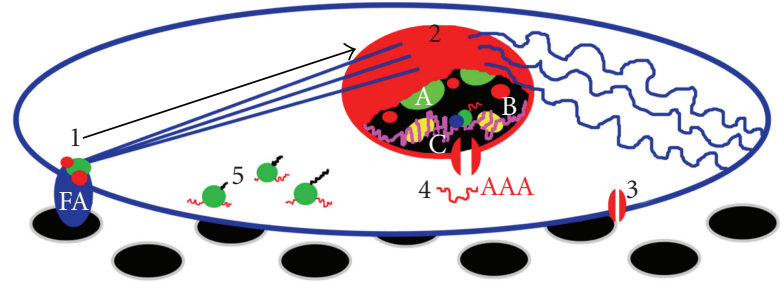

FIGURE 3: Summary of potential mechanical effects of nanotopography on a generic cell of mesenchymal origin. (1) Cell sensing of the nanotopographical stimulus (black circles) is initiated at focal adhesions (FA), with protein recruitment, force-induced changes in protein conformation and binding at these sites, cytoskeletal remodelling and indirect chemical signalling to the nucleus (arrow). (2) Physical forces from the cytoskeleton, including tension from actin stress fibres (straight lines) and interactions between actin and the intermediate filaments vimentin (wavy lines) and the lamins (red) induce direct mechanotransductive effects. Together with signalling inputs, these changes may include redistribution of chromosomes, nucleoli (A), and other nuclear components (B), epigenetic changes to DNA (pink) and histones (yellow), and accessibility of DNA to the transcriptional machinery (C). (3) Ion channels and certain membrane proteins may also be responsive to the nanofeatures, leading to ion fluxes and additional signals. (4) The diameter of nuclear pores (red channel) may be manipulated by force from the cytoskeleton, potentially affecting mRNA transport. (5) Availability of mRNA, or other modulation of translation, could alter protein production from ribosomes.

otransduction can be seen. It would be anticipated that direct mechanotransduction would account for most of the physical changes in the cell, such as nuclear reshaping, redefinition of chromosomal territories, force-induced changes in protein conformation, and mechanical alterations (e.g., in nuclear pore diameter) that might manipulate mRNA or protein transport. Conversely, chemical signals (such as integrinlinked signal cascades) would be expected to predominate in inducing the rapid-response modifications in protein activity state. Although one type of mechanotransduction may dominate for a particular functional response, it seems highly likely that the two pathways ultimately act to reinforce each other to generate the complete and apposite cellular response to nanotopography.

Appropriate mechanotransduction is crucial for tissue development and function. This principle was elegantly illustrated in studies of substrate rigidity [2] and nanofeatures $[4,5]$, with both types of mechanical stimuli implicated in the fate determination of skeletal stem cells. Furthermore, an increasing number of pathologies [104] are being linked with defects in mechanotransduction. With the emergence of mechanical stimuli as critical modulators of cellular functionality, nanotopography should prove an excellent tool for development of novel biomaterials capable of promoting desirable cellular behaviour, discouraging unwanted cell responses, and preventing or ameliorating pathological changes.

3.3. Into the Proteome. The previous sections have focussed on the observed and putative gene-level and epigenetic effects 
of micro- and nanoscale topography on cells, specifically stem cells. Naturally, differentiation also involves a change to the protein profile of the cells during the formation of different tissues with distinct functions. This is a critical level of control, since proteins are the principle functional effectors in cells. The cellular proteome is defined as the protein profile of the cell under a specific set of conditions. This has recently been investigated in the context of stem cell response to topography using a comparative approach for assessing the global changes in abundance of protein species between two or more conditions, termed differential in gel electrophoresis, or two dimensional (2D)-fluorescence difference gel electrophoresis (DIGE). This technique, which involves the high-resolution 2D separation of fluorescently labelled protein species using large format gels, has been discussed in detail elsewhere, in the context of cell response to topography and biomaterials [105].

In common with the results discussed for gene-level effects, DIGE studies of osteoprogenitor contact guidance on a microgrooved substrate [106] and the osteogenic NSQ50 surface [20] were also supportive of roles for ERK signalling in the response to topography. A number of distinct proteins were observed to exhibit significant changes in expression between control and test surfaces that suggested that the cells exhibited changes in protein profile that were concurrent with changes in osteoprogenitor phenotype. Many of the observed differentially expressed proteins formed part of the ERK1/2 pathway. In a preliminary study (Kantawong et al., our unpublished observations), 72 hours of osteoprogenitor elongation along microgrooves $(12.5 \mu \mathrm{m}$ width, $2 \mu \mathrm{m}$ depth) produced changes in levels of a number of proteins: laminin binding protein, tropomyosin, myosin light chain 2, tumour protein translational control 1 (TPTC), 14-33zeta, and annexin V. Expression of these proteins was suggestive of higher proliferative activity, via activation of ERK signalling, since expression of annexin $\mathrm{V}$ and 143-3zeta are regulated by ERK1/2 [107, 108]. The 14-3-3 protein family are key regulators of cellular processes such as proliferation, differentiation, senescence and apoptosis [109]. After 4 weeks of culture on microgrooved PCL (polycaprolactone), cells showed slower proliferative activity [106], as suggested, for example, by the down-regulation of ribonuclease/angiogenin inhibitor 1 (RNH1) [110], which functions in binding and inactivating RNase I [111]. Similar results were found following examination of the osteogenic NSQ50 nanotopography, with evidence of the involvement of ERK signalling in downstream regulation of ERK-regulated proteins (e.g., in the upregulation of Hsp70 [112], enolase [113], nucleophosmin [114], osteonectin [115], thioredoxin [116], and galectin-1 [117]). Increased levels of ERK-related proteins went hand-in-hand with observations of rapid mineralization on the topography [20], which confirmed the osteogenic nature of the NSQ50 topography at the protein level.

The ERK1/2 MAPK pathway plays a central role in control of cell proliferation $[113,118]$. The regulation of the G1- to S-phase transition is governed by the concerted action of cyclin-dependent kinases (Cdks) and their regulatory cyclin subunits. Strong activation of ERK1/2 by constitutively active Ras or Raf causes cell cycle arrest in established cell lines by inducing the expression of the Cdk inhibitor p21. ERK signalling is thus regulated by a negative feedback loop, both inducing and retarding proliferation [119-121]. During bone repair, cells must rapidly proliferate to increase cell numbers, and then cease proliferation almost completely, to permit differentiation and formation of osteoid or bone. Both phases are critical for successful bone repair from a skeletal stem cell population. Proliferative control via ERK $1 / 2$ is likely to be critical to the whole process, via both negative and positive control mechanisms, and the proteomic results from differentiating cells on topographically structured substrates were strongly suggestive of such a central role for ERK signalling. Given the importance of phosphorylation events in MAPK and other signalling cascades, investigation of cell-topography interactions using phosphoproteomics (reviewed in [122]), the study of global protein phosphorylation, could be a particularly informative mechanism for probing the signalling pathways in future studies.

\section{Clinical Relevance: Challenges and Applications}

Nanotopographies can be designed to promote or reduce cell adhesion and alter stem cell fate, all of which would be useful attributes for a range of applications in regenerative medicine, including orthopaedics and dentistry. Chemical surface patterning of implants could induce these effects, but topographies should persist better than chemical modification on the devices. Indented features would also be advantageous, as these would be less easily abraded during surgery or in situ wear and tear. A combination of different topographies could be used to differentially functionalise implants for distinct applications, or demarcate particular "zones" within a single device. For the production of orthopaedic implants, for example, this should have value for increasing osseointegration in some regions that could enhance implant fixation, reducing postoperative loosening and failure, while decreasing excessive in-growth into areas that would result in damage to the surrounding bone during surgical revision.

Nanotopographical surface features can be fabricated to have a tightly controlled size and spacing. For surgical applications, the features would need to be patterned into clinically relevant materials, which can be technically demanding. Pillar-like nanofeatures were successfully generated in titanium, however, using a through-mask anodisation approach, and were osteoconductive to skeletal stem cells [123]. Scaling up production of ordered nanotopographies for the generation of whole devices presents logistical challenges, particularly if the features are difficult shapes to manufacture, requiring precision techniques such as electron beam lithography. More readily applied surface modification technologies, such as implant roughening by sand-blasting [124], acid etching [125-127], or plasma immersion ion implantation [128, 129], offer a means to generate less defined arrangements of features of mixed sizes. While this 
can be a useful means of modulating cell adhesion and osseointegration $[124,126,127,129]$, the irreproducible nature of the features is likely to contribute to interimplant discrepancies and variable success rates. Use of complementary micro- and nanotopographies should be valuable in the development of more efficacious prostheses. Hydroxyapatite nanoparticles were used as a top layer on microroughened titanium, for example, to increase osseointegration in a rodent model [125].

Tighter control over feature dimensions should be useful for improving the consistency of patterning between implants. Techniques such as colloidal lithography could be useful for nanostructuring of large areas of devices with more consistent topographies. In addition, chemical vapour deposition (CVD) can be utilised to deposit nanoscale features over large areas, in biocompatible materials such as diamond. Nanocrystalline diamond (NCD) films show promise for promoting cell adhesion and stimulating osteoblastic functions over certain ranges of nanofeatures [130], both of which would be useful for orthopaedics. In addition, NCD films have been shown to stimulate differentiation of neural stem cells [131], which could be valuable in nerve regeneration. The use of growth factors, such as bone morphogenic protein-2 (BMP-2) and transforming growth factor beta-2 (TGF- $\beta 2$ ) could also be useful as implant coatings to stimulate bone formation [132]. The amalgamation of smaller areas of bioactive nanotopographies with prosthesis functionalisation by techniques such as CVD (potentially in conjunction with growth factors) is likely to form an intermediate step during the development of technologies for the translation of defined nanotopographies from academic research to implantable devices.

\section{Conclusions}

There is a wealth of accumulating evidence to demonstrate that maintenance of the undifferentiated state of stem cells and the direction of stem cell fate can be modified by the topographic substratum. Surface features are detected by a variety of mechanosensors, including integrin-linked focal adhesions, which respond to the mechanical constraints of the surface by inducing signalling cascades, such as the ERK-MAPK pathway. Physical pulling of the rearranging cytoskeleton on the nucleus complements the chemical signalling, and, together, such direct and indirect mechanotransduction can modulate nuclear components, altering gene expression to direct stem cell responses and modifying the cellular protein profile concomitantly with the state of differentiation.

The potential for the use of nanotopography as a means of influencing cell behaviour and lineage commitment for scientific studies has obvious advantages in reducing, abolishing, or even enhancing chemical inducers and feeder layers. As our understanding of the molecular and wholecell responses of stem cells to topography increases, there will be enormous scope for the creation of next-generation materials possessing defined features to tailor stem cell fate and functioning to specific laboratory, industrial, and therapeutic applications.

\section{Acknowledgments}

The research in Dr. Dalby's group is funded by awards from BBSRC, EPSRC, University of Glasgow, and the Royal Thai Government. The research in the Oreffo group is funded predominantly by the BBSRC and EPSRC.

\section{References}

[1] R. McBeath, D. M. Pirone, C. M. Nelson, K. Bhadriraju, and C. S. Chen, "Cell shape, cytoskeletal tension, and RhoA regulate stem cell lineage commitment," Developmental Cell, vol. 6, no. 4, pp. 483-495, 2004.

[2] A. J. Engler, S. Sen, H. L. Sweeney, and D. E. Discher, "Matrix elasticity directs stem cell lineage specification," Cell, vol. 126, no. 4, pp. 677-689, 2006.

[3] N. Huebsch, P. R. Arany, A. S. Mao et al., "Harnessing traction-mediated manipulation of the cell/matrix interface to control stem-cell fate," Nature materials, vol. 9, no. 6, pp. 518-526, 2010.

[4] M. J. Dalby, N. Gadegaard, R. Tare et al., "The control of human mesenchymal cell differentiation using nanoscale symmetry and disorder," Nature Materials, vol. 6, no. 12, pp. 997-1003, 2007.

[5] S. Oh, K. S. Brammer, Y. S. J. Li et al., "Stem cell fate dictated solely by altered nanotube dimension," Proceedings of the National Academy of Sciences of the United States of America, vol. 106, no. 7, pp. 2130-2135, 2009.

[6] A. Curtis and C. Wilkinson, "Nantotechniques and approaches in biotechnology," Trends in Biotechnology, vol. 19, no. 3, pp. 97-101, 2001.

[7] A. Curtis and M. Riehle, "Tissue engineering: the biophysical background," Physics in Medicine and Biology, vol. 46, no. 4, pp. R47-R65, 2001.

[8] A. Carrel and M. Burrows, "Culture in vitro of malignant tumors," The Journal of Experimental Medicine, vol. 12, pp. 571-575, 1911.

[9] P. Clark, P. Connolly, A. S. G. Curtis, J. A. Dow, and C. D. Wilkinson, "Topographical control of cell behaviour. I. Simple step cues," Development, vol. 99, no. 3, pp. 439-448, 1987.

[10] C. S. Chen, M. Mrksich, S. Huang, G. M. Whitesides, and D. E. Ingber, "Geometric control of cell life and death," Science, vol. 276, no. 5317, pp. 1425-1428, 1997.

[11] M. J. Dalby, M. O. Riehle, S. J. Yarwood, C. D. W. Wilkinson, and A. S. G. Curtis, "Nucleus alignment and cell signaling in fibroblasts: response to a micro-grooved topography," Experimental Cell Research, vol. 284, no. 2, pp. 274-282, 2003.

[12] S. Britland, H. Morgan, B. Wojiak-Stodart, M. Riehle, A. Curtis, and C. Wilkinson, "Synergistic and hierarchical adhesive and topographic guidance of BHK cells," Experimental Cell Research, vol. 228, no. 2, pp. 313-325, 1996.

[13] B. Wojciak-Stothard, Z. Madeja, W. Korohoda, A. Curtis, and C. Wilkinson, "Activation of macrophage-like cells by multiple grooved substrata. Topographical control of cell behaviour," Cell Biology International, vol. 19, no. 6, pp. 485490, 1995.

[14] F. Kantawong, R. Burchmore, C. D. W. Wilkinson, R. O. C. Oreffo, and M. J. Dalby, "Differential in-gel electrophoresis (DIGE) analysis of human bone marrow osteoprogenitor cell contact guidance," Acta Biomaterialia, vol. 5, no. 4, pp. 11371146, 2009. 
[15] M. J. Dalby, M. O. Riehle, H. Johnstone, S. Affrossman, and A. S. G. Curtis, "In vitro reaction of endothelial cells to polymer demixed nanotopography," Biomaterials, vol. 23, no. 14, pp. 2945-2954, 2002.

[16] J. O. Gallagher, K. F. McGhee, C. D. W. Wilkinson, and M. O. Riehle, "Interaction of animal cells with ordered nanotopography," IEEE Transactions on Nanobioscience, vol. 1, no. 1, pp. 24-28, 2002.

[17] C. C. Berry, G. Campbell, A. Spadiccino, M. Robertson, and A. S. G. Curtis, "The influence of microscale topography on fibroblast attachment and motility," Biomaterials, vol. 25, no. 26, pp. 5781-5788, 2004.

[18] M. J. Dalby, M. O. Riehle, H. J. H. Johnstone, S. Affrossman, and A. S. G. Curtis, "Polymer-demixed nanotopography: control of fibroblast spreading and proliferation," Tissue Engineering, vol. 8, no. 6, pp. 1099-1108, 2002.

[19] M. J. Dalby, C. C. Berry, M. O. Riehle, D. S. Sutherland, H. Agheli, and A. S. G. Curtis, "Attempted endocytosis of nanoenvironment produced by colloidal lithography by human fibroblasts," Experimental Cell Research, vol. 295, no. 2, pp. 387-394, 2004.

[20] F. Kantawong, R. Burchmore, N. Gadegaard, R. O. C. Oreffo, and M. J. Dalby, "Proteomic analysis of human osteoprogenitor response to disordered nanotopography," Journal of the Royal Society Interface, vol. 6, no. 40, pp. 10751086, 2009.

[21] F. Kantawong, K. E. V. Burgess, K. Jayawardena et al., "Whole proteome analysis of osteoprogenitor differentiation induced by disordered nanotopography and mediated by ERK signalling," Biomaterials, vol. 30, no. 27, pp. 4723-4731, 2009.

[22] M. J. Dalby, S. J. Yarwood, M. O. Riehle, H. J. H. Johnstone, S. Affrossman, and A. S. G. Curtis, "Increasing fibroblast response to materials using nanotopography: morphological and genetic measurements of cell response to 13-nm-high polymer demixed islands," Experimental Cell Research, vol. 276, no. 1, pp. 1-9, 2002.

[23] R. L. Price, K. M. Haberstroh, and T. J. Webster, "Enhanced functions of osteoblasts on nanostructed surfaces of carbon and alumina," Medical and Biological Engineering and Computing, vol. 41, no. 3, pp. 372-375, 2003.

[24] T. J. Webster, C. Ergun, R. H. Doremus, R. W. Siegel, and R. Bizios, "Enhanced osteoclast-like cell functions on nanophase ceramics," Biomaterials, vol. 22, no. 11, pp. 13271333, 2001.

[25] D. Geblinger, L. Addadi, and B. Geiger, "Nano-topography sensing by osteoclasts," Journal of Cell Science, vol. 123, no. 9, pp. 1503-1510, 2010.

[26] A. Thapa, T. J. Webster, and K. M. Haberstroh, "Polymers with nano-dimensional surface features enhance bladder smooth muscle cell adhesion," Journal of Biomedical Materials Research A, vol. 67, no. 4, pp. 1374-1383, 2003.

[27] A.-S. Andersson, F. Bäckhed, A. Von Euler, A. RichterDahlfors, D. Sutherland, and B. Kasemo, "Nanoscale features influence epithelial cell morphology and cytokine production," Biomaterials, vol. 24, no. 20, pp. 3427-3436, 2003.

[28] A.-S. Andersson, J. Brink, U. Lidberg, and D. S. Sutherland, "Influence of systematically varied nanoscale topography on the morphology of epithelial cells," IEEE Transactions on Nanobioscience, vol. 2, no. 2, pp. 49-57, 2003.

[29] M. J. Dalby, M. O. Riehle, H. Johnstone, S. Affrossman, and A. S. G. Curtis, "Investigating the limits of filopodial sensing: a brief report using SEM to image the interaction between 10-nm high nano-topography and fibroblast filopodia," Cell Biology International, vol. 28, no. 3, pp. 229-236, 2004.

[30] C. Vieu, F. Carcenac, A. Pépin et al., "Electron beam lithography: resolution limits and applications," Applied Surface Science, vol. 164, no. 1-4, pp. 111-117, 2000.

[31] N. Gadegaard, S. Thoms, D. S. Macintyre et al., "Arrays of nano-dots for cellular engineering," Microelectronic Engineering, vol. 67-68, pp. 162-168, 2003.

[32] C. D. W. Wilkinson, M. Riehle, M. Wood, J. Gallagher, and A. S. G. Curtis, "The use of materials patterned on a nano- and micro-metric scale in cellular engineering," Materials Science and Engineering C, vol. 19, no. 1-2, pp. 263-269, 2002.

[33] S. Affrossman, G. Henn, S. A. O’Neill, R. A. Pethrick, and M. Stamm, "Surface topography and composition of deuterated polystyrene-poly(bromostyrene) blends," Macromolecules, vol. 29, no. 14, pp. 5010-5016, 1996.

[34] S. Affrossman, S. A. O’Neill, and M. Stamm, “Topography and surface composition of thin films of blends of polystyrene with brominated polystyrenes: effects of varying the degree of bromination and annealing," Macromolecules, vol. 31, no. 18, pp. 6280-6288, 1998.

[35] F. A. Denis, P. Hanarp, D. S. Sutherland, and Y. F. Dufrêne, "Fabrication of nanostructured polymer surfaces using colloidal lithography and spin-coating," Nano Letters, vol. 2, no. 12, pp. 1419-1425, 2002.

[36] S. MacNeil, "Progress and opportunities for tissueengineered skin," Nature, vol. 445, no. 7130 , pp. 874-880, 2007.

[37] P. Macchiarini, P. Jungebluth, T. Go et al., "Clinical transplantation of a tissue-engineered airway," The Lancet, vol. 372, no. 9655, pp. 2023-2030, 2008.

[38] A. Atala, S. B. Bauer, S. Soker, J. J. Yoo, and A. B. Retik, "Tissue-engineered autologous bladders for patients needing cystoplasty," Lancet, vol. 367, no. 9518, pp. 1241-1246, 2006.

[39] N. Bigdeli, M. Andersson, R. Strehl et al., "Adaptation of human embryonic stem cells to feeder-free and matrix-free culture conditions directly on plastic surfaces," Journal of Biotechnology, vol. 133, no. 1, pp. 146-153, 2008.

[40] K. Takahashi and S. Yamanaka, "Induction of pluripotent stem cells from mouse embryonic and adult fibroblast cultures by defined factors," Cell, vol. 126, no. 4, pp. 663-676, 2006.

[41] K. Okita, T. Ichisaka, and S. Yamanaka, "Generation of germline-competent induced pluripotent stem cells," Nature, vol. 448, no. 7151, pp. 313-317, 2007.

[42] K. Woltjen, I. P. Michael, P. Mohseni et al., "piggyBac transposition reprograms fibroblasts to induced pluripotent stem cells," Nature, vol. 458, no. 7239, pp. 766-770, 2009.

[43] S. Levenberg, N. F. Huang, E. Lavik, A. B. Rogers, J. ItskovitzEldor, and R. Langer, "Differentiation of human embryonic stem cells on three-dimensional polymer scaffolds," Proceedings of the National Academy of Sciences of the United States of America, vol. 100, no. 22, pp. 12741-12746, 2003.

[44] L. A. Smith, X. Liu, J. Hu, and P. X. Ma, "The influence of three-dimensional nanofibrous scaffolds on the osteogenic differentiation of embryonic stem cells," Biomaterials, vol. 30, no. 13, pp. 2516-2522, 2009.

[45] D. F. McFarlin, K. J. Finn, P. F. Nealey, and C. J. Murphy, "Nanoscale topography modulates human embryonic stem cell self-renewal," in Proceedings of the 46th Annual Meeting of The American Society for Cell Biology, 2006.

[46] A. Nur-E-Kamal, I. Ahmed, J. Kamal, M. Schindler, and S. Meiners, "Three-dimensional nanofibrillar surfaces promote 
self-renewal in mouse embryonic stem cells," Stem Cells, vol. 24, no. 2, pp. 426-433, 2006.

[47] R. S. Tare, J. C. Babister, J. Kanczler, and R. O. C. Oreffo, "Skeletal stem cells: phenotype, biology and environmental niches informing tissue regeneration," Molecular and Cellular Endocrinology, vol. 288, no. 1-2, pp. 11-21, 2008.

[48] M. F. Pittenger, A. M. Mackay, S. C. Beck et al., "Multilineage potential of adult human mesenchymal stem cells," Science, vol. 284, no. 5411, pp. 143-147, 1999.

[49] A. Muraglia, R. Cancedda, and R. Quarto, "Clonal mesenchymal progenitors from human bone marrow differentiate in vitro according to a hierarchical model," Journal of Cell Science, vol. 113, no. 7, pp. 1161-1166, 2000.

[50] Y. Narita, A. Yamawaki, H. Kagami, M. Ueda, and Y. Ueda, "Effects of transforming growth factor-beta 1 and ascorbic acid on differentiation of human bone-marrowderived mesenchymal stem cells into smooth muscle cell lineage," Cell and Tissue Research, vol. 333, no. 3, pp. 449459, 2008.

[51] N. Bertani, P. Malatesta, G. Volpi, P. Sonego, and R. Perris, "Neurogenic potential of human mesenchymal stem cells revisited: analysis by immunostaining, time-lapse video and microarray," Journal of Cell Science, vol. 118, no. 17, pp. 39253936, 2005.

[52] E. K. F. Yim, S. W. Pang, and K. W. Leong, "Synthetic nanostructures inducing differentiation of human mesenchymal stem cells into neuronal lineage," Experimental Cell Research, vol. 313, no. 9, pp. 1820-1829, 2007.

[53] G. S. Stein and J. B. Lian, "Molecular mechanisms mediating proliferation/differentiation interrelationships during progressive development of the osteoblast phenotype," Endocrine Reviews, vol. 14, no. 4, pp. 424-442, 1993.

[54] R. J. McMurray, N. Gadegaard, R. O. C. Oreffo, and M. J. Dalby, "A temporal study of skeletal stem cell differentiation following culture on substrates patterned with a novel nanopattern containing controlled disorder," in preparation.

[55] M. R. Lee, K. W. Kwon, H. Jung et al., "Direct differentiation of human embryonic stem cells into selective neurons on nanoscale ridge/groove pattern arrays," Biomaterials, vol. 31, no. 15, pp. 4360-4366, 2010.

[56] F. Zhao, J. J. Veldhuis, Y. Duan et al., "Low oxygen tension and synthetic nanogratings improve the uniformity and stemness of human mesenchymal stem cell layer," Molecular Therapy, vol. 18, no. 5, pp. 1010-1018, 2010.

[57] A. Tsuruma, M. Tanaka, S. Yamamoto, and M. Shimomura, "Control of neural stem cell differentiation on honeycomb films," Colloids and Surfaces A, vol. 313-314, pp. 536-540, 2008.

[58] J. B. Recknor, D. S. Sakaguchi, and S. K. Mallapragada, "Directed growth and selective differentiation of neural progenitor cells on micropatterned polymer substrates," Biomaterials, vol. 27, no. 22, pp. 4098-4108, 2006.

[59] G. T. Christopherson, H. Song, and H.-Q. Mao, "The influence of fiber diameter of electrospun substrates on neural stem cell differentiation and proliferation," Biomaterials, vol. 30, no. 4, pp. 556-564, 2009.

[60] S. Yamamoto, M. Tanaka, H. Sunami et al., "Relationship between adsorbed fibronectin and cell adhesion on a honeycomb-patterned film," Surface Science, vol. 600, no. 18, pp. 3785-3791, 2006.

[61] M. Arnold, E. A. Cavalcanti-Adam, R. Glass et al., "Activation of integrin function by nanopatterned adhesive interfaces," ChemPhysChem, vol. 5, no. 3, pp. 383-388, 2004.
[62] M. J. P. Biggs, R. G. Richards, N. Gadegaard, C. D. W. Wilkinson, and M. J. Dalby, "The effects of nanoscale pits on primary human osteoblast adhesion formation and cellular spreading," Journal of Materials Science: Materials in Medicine, vol. 18, no. 2, pp. 399-404, 2007.

[63] M. J. Dalby, M. J. P. Biggs, N. Gadegaard, G. Kalna, C. D. W. Wilkinson, and A. S. G. Curtis, "Nanotopographical stimulation of mechanotransduction and changes in interphase centromere positioning," Journal of Cellular Biochemistry, vol. 100, no. 2, pp. 326-338, 2007.

[64] J. Park, S. Bauer, K. von der Mark, and P. Schmuki, "Nanosize and vitality: $\mathrm{TiO}_{2}$ nanotube diameter directs cell fate," Nano Letters, vol. 7, no. 6, pp. 1686-1691, 2007.

[65] M. J. P. Biggs, R. G. Richards, S. McFarlane, C. D. W. Wilkinson, R. O. C. Oreffo, and M. J. Dalby, "Adhesion formation of primary human osteoblasts and the functional response of mesenchymal stem cells to $330 \mathrm{~nm}$ deep microgrooves," Journal of the Royal Society Interface, vol. 5, no. 27, pp. 12311242, 2008.

[66] E. A. Cavalcanti-Adam, T. Volberg, A. Micoulet, H. Kessler, B. Geiger, and J. P. Spatz, "Cell spreading and focal adhesion dynamics are regulated by spacing of integrin ligands," Biophysical Journal, vol. 92, no. 8, pp. 2964-2974, 2007.

[67] M. J. Dalby, M. O. Riehle, H. J. H. Johnstone, S. Affrossman, and A. S. G. Curtis, "Nonadhesive nanotopography: fibroblast response to poly(n-butyl methacrylate)-poly(styrene) demixed surface features," Journal of Biomedical Materials Research A, vol. 67, no. 3, pp. 1025-1032, 2003.

[68] E. A. Cavalcanti-Adam, A. Micoulet, J. Blümmel, J. Auernheimer, H. Kessler, and J. P. Spatz, "Lateral spacing of integrin ligands influences cell spreading and focal adhesion assembly," European Journal of Cell Biology, vol. 85, no. 3-4, pp. 219-224, 2006.

[69] M. J. Dalby, D. Giannaras, M. O. Riehle, N. Gadegaard, S. Affrossman, and A. S. G. Curtis, "Rapid fibroblast adhesion to $27 \mathrm{~nm}$ high polymer demixed nano-topography," Biomaterials, vol. 25, no. 1, pp. 77-83, 2004.

[70] T. Sjöström, M. J. Dalby, A. Hart, R. Tare, R. O. C. Oreffo, and B. Su, "Fabrication of pillar-like titania nanostructures on titanium and their interactions with human skeletal stem cells," Acta Biomaterialia, vol. 5, no. 5, pp. 1433-1441, 2009.

[71] M. D. Schaller, C. A. Borgman, B. S. Cobb, R. R. Vines, A. B. Reynolds, and J. T. Parsons, "pp125(FAK), a structurally distinctive protein-tyrosine kinase associated with focal adhesions," Proceedings of the National Academy of Sciences of the United States of America, vol. 89, no. 11, pp. 5192-5196, 1992.

[72] R. K. Jaiswal, N. Jaiswal, S. P. Bruder, G. Mbalaviele, D. R. Marshak, and M. F. Pittenger, "Adult human mesenchymal stem cell differentiation to the osteogenic or adipogenic lineage is regulated by mitogen-activated protein kinase," Journal of Biological Chemistry, vol. 275, no. 13, pp. 96459652, 2000.

[73] R. F. Klees, R. M. Salasznyk, K. Kingsley, W. A. Williams, A. Boskey, and G. E. Plopper, "Laminin-5 induces osteogenic gene expression in human mesenchymal stem cells through an ERK-dependent pathway," Molecular Biology of the Cell, vol. 16, no. 2, pp. 881-890, 2005.

[74] C. Ge, G. Xiao, D. Jiang, and R. T. Franceschi, "Critical role of the extracellular signal-regulated kinase-MAPK pathway in osteoblast differentiation and skeletal development," Journal of Cell Biology, vol. 176, no. 5, pp. 709-718, 2007. 
[75] E. Kokubu, D. W. Hamilton, T. Inoue, and D. M. Brunette, "Modulation of human gingival fibroblast adhesion, morphology, tyrosine phosphorylation, and ERK 1/2 localization on polished, grooved and SLA substratum topographies," Journal of Biomedical Materials Research A, vol. 91, no. 3, pp. 663-670, 2009.

[76] D. W. Hamilton and D. M. Brunette, "The effect of substratum topography on osteoblast adhesion mediated signal transduction and phosphorylation," Biomaterials, vol. 28, no. 10, pp. 1806-1819, 2007.

[77] J. Liu, X. He, S. A. Corbett et al., "Integrins are required for the differentiation of visceral endoderm," Journal of Cell Science, vol. 122, no. 2, pp. 233-242, 2009.

[78] K. L. Yee, V. M. Weaver, and D. A. Hammer, "Integrinmediated signalling through the MAP-kinase pathway," IET Systems Biology, vol. 2, no. 1, pp. 8-15, 2008.

[79] A. Hart, N. Gadegaard, C. D. W. Wilkinson, R. O. C. Oreffo, and M. J. Dalby, "Osteoprogenitor response to lowadhesion nanotopographies originally fabricated by electron beam lithography," Journal of Materials Science: Materials in Medicine, vol. 18, no. 6, pp. 1211-1218, 2007.

[80] M. J. P. Biggs, R. G. Richards, N. Gadegaard, C. D. W. Wilkinson, and M. J. Dalby, "Regulation of implant surface cell adhesion: characterization and quantification of Sphase primary osteoblast adhesions on biomimetic nanoscale substrates," Journal of Orthopaedic Research, vol. 25, no. 2, pp. 273-282, 2007.

[81] M. C. Subauste, O. Pertz, E. D. Adamson, C. E. Turner, S. Junger, and K. M. Hahn, "Vinculin modulation of paxillinFAK interactions regulates ERK to control survival and motility," Journal of Cell Biology, vol. 165, no. 3, pp. 371-381, 2004.

[82] R. M. Salasznyk, R. F. Klees, A. Boskey, and G. E. Plopper, "Activation of FAK is necessary for the osteogenic differentiation of human mesenchymal stem cells on laminin-5," Journal of Cellular Biochemistry, vol. 100, no. 2, pp. 499-514, 2007.

[83] J. L. Rodriguez Fernandez and A. Ben-Ze'ev, "Regulation of fibronectin, integrin and cytoskeleton expression in differentiating adipocytes: inhibition by extracellular matrix and polylysine," Differentiation, vol. 42, no. 2, pp. 65-74, 1989.

[84] J.-J. Li and D. Xie, "Cleavage of focal adhesion kinase (FAK) is essential in adipocyte differentiation," Biochemical and Biophysical Research Communications, vol. 357, no. 3, pp. 648-654, 2007.

[85] W. Luo, H. Shitaye, M. Friedman et al., "Disruption of cell-matrix interactions by heparin enhances mesenchymal progenitor adipocyte differentiation," Experimental Cell Research, vol. 314, no. 18, pp. 3382-3391, 2008.

[86] M. J. P. Biggs, R. G. Richards, N. Gadegaard et al., "Interactions with nanoscale topography: adhesion quantification and signal transduction in cells of osteogenic and multipotent lineage," Journal of Biomedical Materials Research A, vol. 91, no. 1, pp. 195-208, 2009.

[87] M. J. Dalby, N. Gadegaard, and C. D. W. Wilkinson, "The response of fibroblasts to hexagonal nanotopography fabricated by electron beam lithography," Journal of Biomedical Materials Research A, vol. 84, no. 4, pp. 973-979, 2008.

[88] D. Riveline, E. Zamir, N. Q. Balaban et al., "Focal contacts as mechanosensors: externally applied local mechanical force induces growth of focal contacts by an mDial-dependent and ROCK-independent mechanism," Journal of Cell Biology, vol. 153, no. 6, pp. 1175-1186, 2001.
[89] J. C. Friedland, M. H. Lee, and D. Boettiger, "Mechanically activated integrin switch controls $\alpha 5 \beta 1$ function," Science, vol. 323, no. 5914, pp. 642-644, 2009.

[90] S. Li, P. Butler, Y. Wang et al., "The role of the dynamics of focal adhesion kinase in the mechanotaxis of endothelial cells," Proceedings of the National Academy of Sciences of the United States of America, vol. 99, no. 6, pp. 3546-3551, 2002.

[91] Y. Sawada and M. P. Sheetz, "Force transduction by Triton cytoskeletons," Journal of Cell Biology, vol. 156, no. 4, pp. 609-615, 2002.

[92] A. del Rio, R. Perez-Jimenez, R. Liu, P. Roca-Cusachs, J. M. Fernandez, and M. P. Sheetz, "Stretching single talin rod molecules activates vinculin binding," Science, vol. 323, no. 5914, pp. 638-641, 2009.

[93] Y. Sawada, M. Tamada, B. J. Dubin-Thaler et al., "Force sensing by mechanical extension of the Src family kinase substrate p130Cas," Cell, vol. 127, no. 5, pp. 1015-1026, 2006.

[94] X.-H. Zhao, C. Laschinger, P. Arora, K. Szászi, A. Kapus, and C. A. McCulloch, "Force activates smooth muscle $\alpha$ actin promoter activity through the Rho signaling pathway," Journal of Cell Science, vol. 120, no. 10, pp. 1801-1809, 2007.

[95] V. Vogel and M. Sheetz, "Local force and geometry sensing regulate cell functions," Nature Reviews Molecular Cell Biology, vol. 7, no. 4, pp. 265-275, 2006.

[96] N. Wang, K. Naruse, D. Stamenović et al., "Mechanical behavior in living cells consistent with the tensegrity model," Proceedings of the National Academy of Sciences of the United States of America, vol. 98, no. 14, pp. 7765-7770, 2001.

[97] F. Haque, D. J. Lloyd, D. T. Smallwood et al., "SUN1 interacts with nuclear lamin A and cytoplasmic nesprins to provide a physical connection between the nuclear lamina and the cytoskeleton," Molecular and Cellular Biology, vol. 26, no. 10, pp. 3738-3751, 2006.

[98] K. A. Kilian, B. Bugarija, B. T. Lahn, and M. Mrksich, "Geometric cues for directing the differentiation of mesenchymal stem cells," Proceedings of the National Academy of Sciences of the United States of America, vol. 107, no. 11, pp. 4872-4877, 2010.

[99] A. Mazumder and G. V. Shivashankar, "Gold-nanoparticleassisted laser perturbation of chromatin assembly reveals unusual aspects of nuclear architecture within living cells," Biophysical Journal, vol. 93, no. 6, pp. 2209-2216, 2007.

[100] A. J. Maniotis, K. Bojanowski, and D. E. Ingber, "Mechanical continuity and reversible chromosome disassembly within intact genomes removed from living cells," Journal of Cellular Biochemistry, vol. 65, no. 1, pp. 114-130, 1997.

[101] A. J. Maniotis, C. S. Chen, and D. E. Ingber, "Demonstration of mechanical connections between integrins, cytoskeletal filaments, and nucleoplasm that stabilize nuclear structure," Proceedings of the National Academy of Sciences of the United States of America, vol. 94, no. 3, pp. 849-854, 1997.

[102] S. L. Berger, "The complex language of chromatin regulation during transcription," Nature, vol. 447, no. 7143, pp. 407412, 2007.

[103] N. Wang, J. D. Tytell, and D. E. Ingber, "Mechanotransduction at a distance: mechanically coupling the extracellular matrix with the nucleus," Nature Reviews Molecular Cell Biology, vol. 10, no. 1, pp. 75-82, 2009.

[104] D. E. Jaalouk and J. Lammerding, "Mechanotransduction gone awry," Nature Reviews Molecular Cell Biology, vol. 10, no. 1, pp. 63-73, 2009.

[105] L. E. McNamara, M. J. Dalby, M. O. Riehle, and R. Burchmore, "Fluorescence two-dimensional difference gel electrophoresis for biomaterial applications," Journal of the 
Royal Society Interface, vol. 7, supplement 1, pp. S107-S118, 2010.

[106] F. Kantawong, R. Burchmore, C. D.W. Wilkinson, R. O.C. Oreffo, and M. J. Dalby, "Differential in-gel electrophoresis (DIGE) analysis of human bone marrow osteoprogenitor cell contact guidance," Acta Biomaterialia, vol. 5, no. 4, pp. 11371146, 2009.

[107] Y. Konishi, H. Sato, and T. Tanaka, "Anisomycin superinduces annexin V mRNA expression through the ERK1/2 but not the p38 MAP kinase pathway," Biochemical and Biophysical Research Communications, vol. 313, no. 4, pp. 977-983, 2004.

[108] W. Yan, Y. Ding, and H.-H. Tai, " $14-3-3 \zeta$ interacts with human thromboxane receptors and is involved in the agonist-induced activation of the extracellular-signalregulated kinase," Biochemical Pharmacology, vol. 71, no. 5, pp. 624-633, 2006.

[109] M. Niemantsverdriet, K. Wagner, M. Visser, and C. Backendorf, "Cellular functions of $14-3-3 \zeta$ in apoptosis and cell adhesion emphasize its oncogenic character," Oncogene, vol. 27, no. 9, pp. 1315-1319, 2008.

[110] V. Nobile, N. Russo, G.-F. Hu, and J. F. Riordan, "Inhibition of human angiogenin by DNA aptamers: nuclear colocalization of an angiogenin-inhibitor complex," Biochemistry, vol. 37, no. 19, pp. 6857-6863, 1998.

[111] K. A. Dickson, M. C. Haigis, and R. T. Raines, "Ribonuclease inhibitor: structure and function," Progress in Nucleic Acid Research and Molecular Biology, vol. 80, pp. 349-374, 2005.

[112] J. M. Keller, J. F. Escara-Wilke, and E. T. Keller, "Heat stressinduced heat shock protein 70 expression is dependent on ERK activation in zebrafish (Danio rerio) cells," Comparative Biochemistry and Physiology A, vol. 150, no. 3, pp. 307-314, 2008.

[113] L. P. Sousa, B. M. Silva, B. S. A. F. Brasil et al., "Plasminogen/plasmin regulates $\alpha$-enolase expression through the MEK/ERK pathway," Biochemical and Biophysical Research Communications, vol. 337, no. 4, pp. 1065-1071, 2005.

[114] C.-W. Yeh, S.-S. Huang, R.-P. Lee, and B. Y.-M. Yung, "Ras-dependent recruitment of c-Myc for transcriptional activation of nucleophosmin/B23 in highly malignant U1 bladder cancer cells," Molecular Pharmacology, vol. 70, no. 4, pp. 1443-1453, 2006.

[115] Y. Kato, J.-M. Lewalle, Y. Baba et al., "Induction of SPARC by VEGF in human vascular endothelial cells," Biochemical and Biophysical Research Communications, vol. 287, no. 2, pp. 422-426, 2001.

[116] M.-R. Kim, H.-S. Chang, B.-H. Kim et al., "Involvements of mitochondrial thioredoxin reductase (TrxR2) in cell proliferation," Biochemical and Biophysical Research Communications, vol. 304, no. 1, pp. 119-124, 2003.

[117] M. B. Fuertes, L. L. Molinero, M. A. Toscano et al., "Regulated expression of galectin-1 during T-cell activation involves Lck and Fyn kinases and signaling through MEK1/ERK, p38 MAP kinase and p70S6 kinase," Molecular and Cellular Biochemistry, vol. 267, no. 1-2, pp. 177-185, 2004.

[118] S. Meloche and J. Pouysségur, "The ERK1/2 mitogenactivated protein kinase pathway as a master regulator of the G1- to S-phase transition," Oncogene, vol. 26, no. 22, pp. 3227-3239, 2007.

[119] K. Yeung, P. Janosch, B. McFerran et al., "Mechanism of suppression of the Raf/MEK/extracellular signal-regulated kinase pathway by the Raf kinase inhibitor protein," Molecular and Cellular Biology, vol. 20, no. 9, pp. 3079-3085, 2000.

[120] N. A. Zeliadt, L. J. Mauro, and E. V. Wattenberg, "Reciprocal regulation of extracellular signal regulated kinase $1 / 2$ and mitogen activated protein kinase phosphatase-3," Toxicology and Applied Pharmacology, vol. 232, no. 3, pp. 408-417, 2008.

[121] A. von Kriegsheim, A. Pitt, G. J. Grindlay, W. Kolch, and A. S. Dhillon, "Regulation of the Raf-MEK-ERK pathway by protein phosphatase 5," Nature Cell Biology, vol. 8, no. 9, pp. 1011-1016, 2006.

[122] S. de la Fuente van Bentem, W. I. Mentzen, A. de la Fuente, and H. Hirt, "Towards functional phosphoproteomics by mapping differential phosphorylation events in signaling networks," Proteomics, vol. 8, no. 21, pp. 4453-4465, 2008.

[123] T. Sjöström, M. J. Dalby, A. Hart, R. Tare, R. O. C. Oreffo, and B. Su, "Fabrication of pillar-like titania nanostructures on titanium and their interactions with human skeletal stem cells," Acta Biomaterialia, vol. 5, no. 5, pp. 1433-1441, 2009.

[124] G.-L. Yang, F.-M. He, X.-F. Yang, X.-X. Wang, and S.-F. Zhao, "Bone responses to titanium implants surface-roughened by sandblasted and double etched treatments in a rabbit model," Oral Surgery, Oral Medicine, Oral Pathology, Oral Radiology and Endodontology, vol. 106, no. 4, pp. 516-524, 2008.

[125] I. Nishimura, Y. Huang, F. Butz, T. Ogawa, A. Lin, and C. J. Wang, "Discrete deposition of hydroxyapatite nanoparticles on a titanium implant with predisposing substrate microtopography accelerated osseointegration," Nanotechnology, vol. 18, no. 24, Article ID 245101, 2007.

[126] S. A. Hacking, E. J. Harvey, M. Tanzer, J. J. Krygier, and J. D. Bobyn, "Acid-etched microtexture for enhancement of bone growth into porous-coated implants," Journal of Bone and Joint Surgery. Series B, vol. 85, no. 8, pp. 1182-1189, 2003.

[127] S.-A. Cho and K.-T. Park, "The removal torque of titanium screw inserted in rabbit tibia treated by dual acid etching," Biomaterials, vol. 24, no. 20, pp. 3611-3617, 2003.

[128] M. Rinner, J. Gerlach, and W. Ensinger, "Formation of titanium oxide films on titanium and Ti6A14V by $\mathrm{O}_{2}$ plasma immersion ion implantation," Surface and Coatings Technology, vol. 132, no. 2-3, pp. 111-116, 2000.

[129] S. Mändl, R. Sader, G. Thorwarth et al., "Investigation on plasma immersion ion implantation treated medical implants," Biomolecular Engineering, vol. 19, no. 2-6, pp. 129132, 2002.

[130] L. Yang, B. W. Sheldon, and T. J. Webster, "The impact of diamond nanocrystallinity on osteoblast functions," Biomaterials, vol. 30, no. 20, pp. 3458-3465, 2009.

[131] Y.-C. Chen, D.-C. Lee, T.-Y. Tsai et al., "Induction and regulation of differentiation in neural stem cells on ultrananocrystalline diamond films," Biomaterials, vol. 31, no. 21, pp. 5575-5587, 2010.

[132] D. R. Sumner, T. M. Turner, R. M. Urban, A. S. Virdi, and N. Inoue, "Additive enhancement of implant fixation following combined treatment with rhTGF- $\beta 2$ and rhBMP2 in a canine model," Journal of Bone and Joint Surgery. Series A, vol. 88, no. 4, pp. 806-817, 2006. 